\section{The performance of various anthropometric assessment methods for predicting low birth weight in pregnant women}

\section{Desempenho de diferentes métodos de avaliação antropométrica de gestantes na predição de baixo peso ao nascer}

Patricia de Carvalho Padilha 1

Elizabeth Accioly 2

Glória Valéria da Veiga 3

Tereza Cristina Bessa 4

Beatriz Della Libera 5

Jamile Lima Nogueira 6

Priscila Dutra Alves 7

Paulo Roberto de Souza Junior 8

Cláudia Saunders 9

1Instituto de Puericultura e Pediatria Martagão Gesteira

Universidade Federal do Rio de Janeiro. Serviço de Nutrição Clínica. Rua Bruno Lobo, n. 50. Ilha do Fundão. Rio de Janeiro, RJ, Brasil. CEP: 21.920-612. E-mail: paticpadilha@yahoo.com.br 2,5-7,9 Instituto de Nutrição Josué de Castro. Departamento de Nutrição e Dietética. Centro de Ciências da Saúde. Universidade Federal do Rio de Janeiro, RJ, Brasil.

3 Departamento de Nutrição Social e Aplicada. Instituto de Nutrição Josué de Castro. Universidade Federal do Rio de Janeiro, RJ, Brasil.

4 Maternidade Escola. Universidade Federal do Rio de Janeiro, RJ, Brasil.

${ }^{8}$ Departamento de Epidemiologia e Métodos Quantitativos em Saúde Pública. Escola Nacional de Saúde Pública Fundação Osvaldo Cruz. Rio de Janeiro, RJ, Brasil.

\begin{abstract}
Objectives: to assess the performance of various anthropometric methods for the evaulation of the nutritional status of pregnant women as a means of predicting low birth weight $(L B W)$.

Methods: a descriptive cross-cutting study carried out among 433 pregnant women ( $\geq 20$ years) attending a Public Maternity Hospital in Rio de Janeiro, Brazil. The adequacy of the weight gain at the end of the pregnancy was evaluated in accordance with the proposals of the Institute of Medicine and the Brazilian Ministry of Health. The sensitivity, specificity and accuracy of the adequacy of weight gain at the end of the pregnancy or nutritional state of mother as a predictor of low birth weight were calculated.

Results: the sensitivity of the various methods varied from $63.1 \%$ to $68.4 \%$ and the specificity from $71.2 \%$ to $75.1 \%$. The adapted Institute of Medicine proposal drawn up by the Brazilian Ministry of Health, according to the classification of the pre-delivery nutritional status of the mother according to the World Health Organization cutoff points showed itself to be the most accurate (74.5\%), this being the most adequate method for nutritional triage for reason of its association with low birth weight $(O R=4.10 ; 95 \% C I=1.53-10.92)$.

Conclusions: the best proposals for this population are those of the Institute of Medicine and the Brazilian Ministry of Health. Further studies aiming to ascertain the most appropriate methods of anthropometric evaluation for different populations should be encouraged.
\end{abstract}

Key words Pregnancy, Anthropometry, Weight gain, Infant, Low birth weight

\section{Resumo}

Objetivos: avaliar o desempenho de diferentes métodos antropométricos para avaliação nutricional de gestantes para predizer o baixo peso ao nascer (BPN).

Métodos: estudo descritivo do tipo transversal, realizado com 433 puérperas ( $\geq 20$ anos) atendidas numa Maternidade Pública do Rio de Janeiro, Brasil. A adequação do ganho de peso ao final da gestação foi avaliada segundo as propostas do Institute of Medicine e do Ministério da Saúde. Calculou-se a sensibilidade, a especificidade e a acurácia das variáveis adequação do ganho de peso gestacional total ou adequação do estado nutricional materno ao final da gestação na predição do $B P N$.

Resultados: a sensibilidade dos métodos variou de adaptação da proposta do Institute of Medicine elaborada pelo Ministério da Saúde, segundo a classificação do estado nutricional pré-gestacional pelos pontos de corte da Organização Mundial da Saúde apresentou maior acurácia (74,5\%), sendo este último o mais adequado para triagem nutricional pela sua associação com o $B P N(O R=4,10$; IC95\%=1,53-10,92).

Conclusões: os melhores para esta população foram as propostas do Institute of Medicine e do Ministério da Saúde. Estudos visando reconhecer os métodos de avaliação antropométrica mais adequados na gestação devem ser estimulados em diferentes populações.

Palavras-chave Gestação, Antropometria, Ganho de peso, Baixo peso ao nascer $63,1 \%$ a $68,4 \%$ e a especificidade de $71,2 \%$ a $75,1 \%$. A 


\section{Introduction}

Maternal nutritional status is considered an important indicator of pregnancy prognosis, birth conditions (especially those related to birth weight) and perinatal mortality. ${ }^{1-4}$ In recent years, an association between low birth weight (LBW) and metabolic disorders has also been demonstrated, and this may have consequences for the development of chronic degenerative diseases in adulthood.5-7

Anthropometric measures are recommended and are the most commonly used method for nutritional follow-up of pregnant women, owing to their importance in preventing perinatal morbimortality, the prognosis of the infant's health and the promotion of women's health.8-10 The importance of anthropometric measures for assessment of the nutritional status of pregnant women is heightened by the fact that they are easy to apply, low-cost, and relatively non-invasive.

Gestational weight gain is important for fetal growth and guidelines with recommendations based on pre-gestational Body Mass Index (BMI) have been proposed over the last decade. 11 However, there are still some questions regarding which method is the best for assessing the nutritional status of pregnant women, and this is of major concern to mother and child health committees. A number of priorities have been identified, foremost among which are addressing lack of definitive and specific recommendations for favorable obstetric outcomes and using appropriate specific indicators for different populations under differing operational conditions. 12,13

Epidemiological studies have drawn attention to the need to test the level of usefulness and efficiency of anthropometric measures in predicting the relevant mother and child outcomes, by identifying the association between specific indicators and the combination of indicators and risk factors for unfavorable obstetric outcomes. 12

Gestational anthropometric assessment measures to be adopted during prenatal care should be easy to apply, low-cost, have a strong capacity to predict undesirable obstetric outcomes, be homogeneous, allow effective intervention, have good sensitivity and specificity in diagnosis, and produce a low number of incorrect classifications. 12

Although there are many different recommendations for performing adequate nutritional monitoring during pregnancy using satisfactory weight gain, anthropometric monitoring during pregnancy remains controversial. Specific problems relating to the reference values available include the facts that these are drawn from population data from old studies where gestational age cannot be evaluated and that they involve a mixture of different ethnic groups and small sample sizes. ${ }^{13}$

Since the beginning of the 1990's, the recommendations of the Institute of Medicine (IOM), ${ }^{14,15}$ has been most commonly employed, and its adoption has been suggested in countries with no official recommendations of their own. ${ }^{12,16}$ This is due to the fact that, when the IOM recommendations were used to evaluate perinatal risks, a direct correlation between maternal nutrition and infant weight was demonstrated. Furthermore, postpartum maternal nutritional status is favored.

As yet, in Brazil, there is no proposal for a reference based on national studies. The Brazilian Ministry of Health has thus been adopting international recommendations for carrying out anthropometric assessment of pregnant Brazilian women. In 2000, the Brazilian Ministry of Health 17 started using the recommendations of the Centro Latinoamericano de Perinatologia (CLAP), 18 which is based on the curve of percentile adequacy of gestational weight gain in relation to gestational age. This defines a range between 8 and $16 \mathrm{~kg}$ as constituting adequate total gestational weight gain, regardless of pre-gestational nutritional status. The present proposal of the Brazilian Ministry of Health, 19 which is being implemented but has yet to be validated for use nationally, is based on the recommendations of Atalah et al.,20 which are based on gestational BMIs associated with ranges of weight gain adapted from the recommendations of the IOM,14,15 which are the most widely used worldwide.

The aim of the present study, therefore, is to evaluate the methods proposed in Brazil for anthropometric assessment of pregnant women to predict low birth weight. These methods are the IOM recommendations 14,15 and the Brazilian Ministry of Health recommendations based on the pre-gestational BMI established by the World Health Organization (WHO) ${ }^{21}$ and on the IOM cut-off points. These have previously been tested and found to be associated with birth weight.

\section{Methods}

This is a cross-sectional descriptive study involving 433 puerperal women ( $\geq 20$ years old) who attended the Maternidade Escola of Universidade Federal do Rio de Janeiro (UFRJ). This Health Unit serves pregnant women whose characteristics are similar to those of pregnant women served by other Public Health Units in the city of Rio de Janeiro, Brazil, in terms of the mother's age and number of prenatal 
care appointments. 22,23

To take part in the study, it was required that the women showed no signs of chronic diseases, had a single-fetus pregnancy, that their pre-gestational weight was known or had been measured by the end of the $13^{\text {th }}$ week of pregnancy, and that they had had access to prenatal care and no dietary restrictions. Data was collected between 1999-2001, and 20052006, respectively.

The data was collected by means of interviews with the women and consultation of their medical records. Before developing the final design, the instruments were pre-tested with pregnant women presenting the same characteristics as the population studied. These data were not included in the final sample. Anthropometric data of both mother and infant were collected from medical records, based on prenatal appointments, as follows.

Data regarding pre-gestational weight was gathered on the basis either of the self-reported weight during prenatal appointments or that measured up to the end of the $13^{\text {th }}$ gestational week, 12 the pre-labor weight or weight measured on the last prenatal care appointment 24 and the height of the mother was measured during the first appointment.

Pre-gestational BMI was calculated on the basis of pre-gestational weight (self-reported or measured) divided by the height squared, and total gestational weight gain was calculated by subtracting pre-gestational weight from the weight measured before labor or on the occasion of the last prenatal care appointment. Adequacy of weight gain was evaluated according to the methodologies proposed by the IOM14,15 and the Brazilian Ministry of Health 17,19 for anthropometric assessment of pregnant women.

The cut-offs used to assess pre-gestational BMI recommended by the IOM are BMI $<19.8 \mathrm{~kg} / \mathrm{m}^{2}$ for low weight; BMI between 19.8 and $26 \mathrm{~kg} / \mathrm{m}^{2}$ for normal weight; BMI between 26 and $29 \mathrm{~kg} / \mathrm{m}^{2}$ for overweight and BMI $>29 \mathrm{~kg} / \mathrm{m} 2$ for obesity. The recommended weight gain ranges are $12.5-18 \mathrm{~kg}$, $11.5-16 \mathrm{~kg}, 7-11.5 \mathrm{~kg}$, e $>7 \mathrm{~kg}$, for low weight, normal weight, overweight and obese pregnant women, respectively.

Because the Brazilian Ministry of Health ${ }^{19}$ does not define cut-off points to be used when classifying pre-gestational nutritional status, the pre-gestational BMI from the $\mathrm{WHO}^{21}$ classification for the adult population was tested. These cut-off points are BMI $<18.5 \mathrm{~kg} / \mathrm{m}^{2}$; BMI between 18.5 and $24.9 \mathrm{~kg} / \mathrm{m}^{2}$; BMI between 25.0 and $29.9 \mathrm{~kg} / \mathrm{m}^{2}$; and BMI $>30$ $\mathrm{kg} / \mathrm{m}^{2}$, for low weight, normal weight, overweight and obesity, respectively.

The evaluation of weight gain adequacy was carried out according to the weight gain ranges recommended for each category of pre-gestational $\mathrm{BMI}$, in order to check if pregnant women had an adequate or inadequate weight gain in relation to their pre-gestational anthropometric classification.

To classify pre-gestational nutritional status according to the Brazilian Ministry of Health, 19 the cut-off points traditionally recommended for pregnant women were also used: BMI $<19.8 \mathrm{~kg} / \mathrm{m}^{2}$ for low weight; BMI between 19.8 and $26 \mathrm{~kg} / \mathrm{m}^{2}$ for normal weight; BMI between 26 and $29 \mathrm{~kg} / \mathrm{m}^{2}$ for overweight and BMI $>29 \mathrm{~kg} / \mathrm{m}^{2}$ for obesity, according to the IOM.14,15 After the classification of the pre-gestational BMI, the weight gain range recommended for each case was established and a comparison of the adequacy of gestational weight gain according to both criteria was carried out.

An evaluation was also carried out of the adequacy of the BMI curve according to the initial BMI situation (pre-gestational or gestational), based on the graph used for monitoring the nutritional status of pregnant women, according to nutritional status classification. 19

Adequacy of gestational weight gain, according to the different methodologies, was broken down into two categories, inadequate (lower than recommended values) and adequate (within or higher than recommended values), as no difference was observed in the birth weight means of infants born to women within or above the normal range.

The anthropometric assessment of infants gathered data on weight, height and gestational age at birth 25 using medical records. Infants were said to present LBW when weight was $<2.5 \mathrm{~kg}$.

To validate the anthropometric assessment methods in relation to the birth weight variable (gold standard), the sensitivity, specificity, positive and negative predictive values, and accuracy were calculated.

With a view to standardizing the procedures for collecting data, the field research team was trained, recycled and supervised.

Data reliability was evaluated and confirmed by way of a re-test applied using the Intraclass Correlation Coefficient (ICC) for continuous variables and the Kappa value $(k)$ for categorical variables. The values for ICC and Kappa were ICC $>0.92$ and $k>0.65$ and ICC $>0.92$ and $k>0.71$, in GII. The concordance between data independently collected by two different researchers accessing the same medical record, randomly selected, was evaluated.

The study was approved by the following Ethics Committees: Comissão de Ética Médica da Universidade Federal do Rio de Janeiro; Comitê de 
Ética em Pesquisa da Escola Nacional de Saúde Pública da Fundação Oswaldo Cruz (FIOCRUZ) and Comitê de Ética em Pesquisa do Instituto de Puericultura e Pediatria Martagão Gesteira (IPPMG/UFRJ). All participants signed an informed consent form.

Measures of central tendency (mean and standard deviation) and dispersion of continuous variables were calculated as part of the exploratory analysis of data.

The agreement between the classification criteria of pre-gestational BMI proposed by the $\mathrm{WHO}^{21}$ and the IOM 14,15 was tested using weighted Kappa statistics.

The odds ratio (OR) and 95\% confidence interval $(95 \% \mathrm{CI})$ for association between the exposure factors and the response variable were calculated using logistic regression.

Subsequently, multiple logistic regression was carried out using variables that presented significance levels lower than $25 \%$ on bivariate analysis, as recommended by Hosmer and Lemeshow, 26 with a view to determining which factors were the most strongly associated with the outcome. In all tests, a significance level of $5 \%$ was established. The number of prenatal nutritional appointments and inadequacy of weight gain variables were retained in the model, according to the IOM;14,15 and inadequacy of weight gain alone, according to the Brazilian Ministry of Health, 19 taking into consideration the different cut-off points adopted. $14,15,21$

The sensitivity and specificity of different methodologies, which appeared to be significantly associated with the outcome of interest, were estimated.

Statistical analysis was performed using the SPSS statistical package for Windows version 13.0.

\section{Results}

Table 1 shows that the mean age for the mother was 27 years $( \pm 5.09)$, and mean number of prenatal care appointments $8.24( \pm 2.46)$. Prenatal nutritional assistance was given to $58.7 \%(n=254)$ of the sample, but the mean number of appointments with a nutritionist was only $2.26( \pm 2.33)$. LBW appeared in $4.7 \%$ of the sample.

Tabela 1

Means and standard deviations for maternal characteristics. Maternidade Escola da Universidade Federal do Rio de Janeiro; Rio de Janeiro, Brazil.

\begin{tabular}{llr}
\hline Characteristics & N & $\overline{\mathbf{X}} \pm$ SD \\
\hline Age & 433 & $27.00 \pm 5.09$ \\
Height $(\mathrm{m})$ & 422 & $1.59 \pm 0.01$ \\
Pre-gestational BMI $\left(\mathrm{Kg} / \mathrm{m}^{2}\right)$ & 418 & $23.23 \pm 3.81$ \\
Number of pregnancies & 433 & $2.25 \pm 1.47$ \\
Number of prenatal care appointments & 431 & $8.24 \pm 2.46$ \\
Number of prenatal nutritional appointments & 433 & $2.26 \pm 2.33$
\end{tabular}

BMI = Body Mass Index

Table 2 shows the classification and concordance of pre-gestational anthropometric nutritional status, according to the classifications proposed by the IOM 14,15 and the WHO, 25 showing a good level of concordance $(\mathrm{k}=0.72 ; 95 \% \mathrm{CI}=0.66-0.78)$.

The $\mathrm{p} 3$ and $\mathrm{p} 10$ percentiles for the height of the mother were $1.47 \mathrm{~m}$ and $1.51 \mathrm{~m}$, respectively.

The results of the multivariate logistic regression model pointed to a significant association between LBW and the number of prenatal care appointments and inadequacy of weight gain, according to the method proposed by the IOM14,15 and the adaptations made to the American guidelines proposed in
Brazil by the Brazilian Ministry of Health.19 (Table 3).

Table 4 presents the values for the sensitivity (SE), specificity (SP), positive predictive value (PPV), negative predictive value (NPV) and accuracy of these methods for predicting LBW. SE ranged from $63.1 \%$ to $68.4 \%$, and specificity, from $71.2 \%$ to $75.1 \%$, which shows a high level of accuracy for the adaptation of the IOM proposal made by the Brazilian Ministry of Health, 19 using the cut-off points recommended by the $\mathrm{WHO}^{25}$ to classify pregestational nutritional status. 
Tabela 2

Classification of pre-gestational anthropometric nutritional status, according to cut-off points established by the World Health Organization (WHO) and the Institute of Medicine (IOM). Maternidade Escola da Universidade Federal do Rio de Janeiro; Rio de Janeiro, Brazil.

\begin{tabular}{|c|c|c|c|}
\hline \multirow[t]{2}{*}{ Pre-gestational nutritional status } & $\begin{array}{c}\text { WHO }(1995)^{*} \\
(n=418)\end{array}$ & $\begin{array}{c}\text { IOM }\left(1990 ; * * 1992^{* * *}\right) \\
(n=418)\end{array}$ & $\begin{array}{c}\text { Kappa weighed } \\
(95 \% \mathrm{Cl})\end{array}$ \\
\hline & $\%$ & $\%$ & \\
\hline Low weight & 6.2 & 16.3 & \\
\hline Normal & 68.2 & 64.8 & $0.72(0.66-0.78)$ \\
\hline Overweight & 19.9 & 10.5 & \\
\hline Obesity & 5.7 & 8.4 & \\
\hline
\end{tabular}

Sources: WHO (World Health Organization) Maternal anthropometry and pregnancy outcomes. WHO Bulletin. 1955.12 ${ }^{* *}$ IOM (Institute of Medicine). Nutrition during pregnancy and lactation. Whashington, DC 1990.14 ***IOM (Institute of Medicine). Nutrition during pregnancy and lactation. Whashington, DC, 1992.15

Tabela 3

Results of multiple logistic regressions relating to low birth weight. Maternidade Escola da Universidade Federal do Rio de Janeiro; Rio de Janeiro, Brazil.

\begin{tabular}{|c|c|c|c|c|}
\hline Variables & $\beta$ & Adjusted OR & $95 \% \mathrm{Cl}$ & $p$ \\
\hline Number of prenatal care appointments $(n=431)$ & -0.258 & 0.77 & $0.63-0.95$ & 0.015 \\
\hline \multicolumn{5}{|c|}{ Inadequacy of weight gain according to the Institute of } \\
\hline Medicine $(I O M, 1990 ; 1992) .14-15 \quad(n=418)$ & 1.39 & 4.01 & $1.45-11.19$ & 0.007 \\
\hline Number of prenatal care appointments $(n=431)$ & -0.261 & 0.77 & $0.63-0.94$ & 0.012 \\
\hline \multicolumn{5}{|l|}{ Inadequacy of weight gain according to the Brazilian } \\
\hline Ministry of Health (2005).* $19 \quad(n=418)$ & 1.26 & 3.56 & $1.33-9.50$ & 0.011 \\
\hline Number of prenatal care appointments $(n=431)$ & -0.263 & 0.77 & $0.63-0.94$ & 0.012 \\
\hline \multicolumn{5}{|l|}{ Inadequacy of weight gain according to the Brazilian } \\
\hline Ministry of Health $(2005) * * 19(n=418)$ & 1.41 & 4.10 & $1.53-10.92$ & 0.005 \\
\hline
\end{tabular}

* According to adequacy of total gestational weight gain following the established table of weight gain ranges, according to pre-gestational Body Mass Index (BMI) ranges, using the IOM cut-off points. 14, 15 Weight gain among obese women limited to $7 \mathrm{~kg}$ and weight gain recommendation within the lower limit of the range for low-height pregnant women (under $1,57 \mathrm{~m}$ ) was disregarded; ${ }^{* *}$ According to total gestational weight gain adequacy following the weight gain range table, established according to pre-gestational BMI ranges and adopting the WHO12 cut-off points. 
Tabela 4

Evaluation of the performance of anthropometric assessment methods for prediction of birth weight. Maternidade Escola da Universidade Federal do Rio de Janeiro. Rio de Janeiro, Brazil.

\begin{tabular}{lcccc}
\hline Method & $\begin{array}{c}\text { Sensitivity } \\
(\%)\end{array}$ & $\begin{array}{c}\text { Specificity } \\
(\%)\end{array}$ & $\begin{array}{c}\text { Positive predictive } \\
\text { value (\%) }\end{array}$ & $\begin{array}{c}\text { Negative predictive } \\
\text { value (\%) }\end{array}$ \\
\hline $\begin{array}{l}\text { Institute of Medicine14,15 } \\
\text { Brazilian Ministry of }\end{array}$ & 68.4 & 71.2 & 10.2 & 97.8 \\
$\begin{array}{l}\text { Health (2005)*19 } \\
\text { Brazilian Ministry of }\end{array}$ & 63.1 & 72.7 & 10.4 & 97.6 \\
Health (2005)**19 & 63.1 & 75.1 & 10.9 & 97.7 \\
\hline
\end{tabular}

*According to adequacy of total gestational weight gain following the established table of weight gain ranges, according to pre-gestational Body Mass Index (BMI) ranges, using the cut-off points established by the Institute of Medicine. 14,15 Weight gain among obese women limited to $7 \mathrm{~kg}$ and weight gain recommendation within the lower limit of the range for low-height pregnant women (under 1,57 m) was disregarded; ** According to total gestational weight gain adequacy following the weight gain range table, established according to pregestational BMI ranges and adopting the World Health Organization(WHO)12 cut-off points.

\section{Discussion}

The WHO estimates that, every year, about 30 million children are born with LBW,7 which corresponds to about $23.6 \%$ of the world's births. Health committees have consequently been showing growing concern regarding LBW, and the current focus is on preventing metabolic diseases in the long- and medium-term. 7 There is unanimous agreement that there is an association between inadequate pre-gestational anthropometric status and gestational weight gain and LBW. The defining values for LBW are still contested by authors, but lie somewhere in the region of $2500-2999 \mathrm{~g} .27,28$

It has therefore become clear over the past decade that there is a need to review the objectives and the indicators for anthropometric assessment of pregnant women, especially the initial nutritional diagnosis using pre-gestational BMI. 29 The results of this study provide further evidence of the differences that may be observed when classifying pregestational nutritional status according to different BMI cut-off points and this corroborates the results of other studies. ${ }^{30,31}$ Although the IOM recommendations are the ones that are most widely used and recognized, they have come under some criticism for being based on data on a population from a developed country which considers obesity a significant nutritional problem. ${ }^{12,32}$

Moreover, BMI ranges proposed by the American committee are based on data from Metropolitan Life Insurance, 14 which has also been a target of criticism. In view of this, the cut-off points proposed by the $\mathrm{WHO}^{21}$ would appear to be more adequate, as they were established on the basis of their association with morbidity.

Currently, some studies have been using the cutoff points recommended for adult populations by the $\mathrm{WHO}^{25}$ in pre-gestational assessment. This is the most sensitive proposal for diagnosis of overweight weight deviation, which is currently a major public health concern. This criterion is also more specific when classifying low weight subjects, thereby reducing the number of false positives. 30,31

The use of the cut-offs proposed by the $\mathrm{WHO}^{21}$ for prenatal diagnosis are consistent with results found in other studies using the cut-off points proposed by the IOM,14,15 namely, higher risk of gestational diabetes and hypertensive disorders of pregnancy (HDP) among overweight and obese women; and a tendency to intrauterine growth restriction (IGR) among those with low pre-gestational weight. ${ }^{29-33}$ Moreover, Doherty et al. ${ }^{29}$ justify the choice of the cut-off points used owing to the fact that they are more reliable than the weight value alone or the comparison of tables carried out by Metropolitan Life Insurance. ${ }^{14}$

As shown by the results of the multivariate logistic regression, the variables associated with LBW were number of prenatal care appointments and inadequate weight gain, regardless of the anthropometric assessment criteria used.

The promotion of mother and child health, by way of prenatal care, takes into consideration the recommendations of an ideal number and the quality of prenatal care appointments, as established as part of the prenatal care program. The WHO Antenatal Care Randomized Trial 34 considers four prenatal 
care appointments to be the ideal number. In this case, however, a higher number of appointments was nevertheless observed to be a protection factor against LBW.

Vital statistics from the State of São Paulo, Brazil show that an increase in the number of prenatal care appointments from between 0 and 3 to 7 or more, in different groups, has led to a reduction in occurrences of low weight and/or preterm birth from $14 \%$ to $4 \% .35$ It would seem, therefore, that an increase in the number of prenatal care appointments and early diagnosis of risk factors would reduce the number of LBW infants.

Another point that suggests the extreme importance of prenatal care is the rejection of gestational intercurrences by the logistic regression model, which indicates efficient care and good quality harm prevention. On the other hand, the rejection of prenatal nutritional assistance may have been due merely to the mean number of appointments $(2.46 \pm 2.33)$, which was lower than that recommended, which is, ideally, four throughout pregnancy or, at least, one in each trimester.

Helms et al. 36 have explored the risks that inappropriate weight gain might bring for obstetric outcomes, pointing out that pregnant women whose weight gain was inadequate presented higher chances (OR=1.78; RI95\% 1.7-1.86) of having LBW babies than those whose weight gain was adequate or excessive. The authors considered the classification of pre-gestational nutritional status using the IOM14 cut-off points as a limitation of the study.

In this study, the significance levels of association found between insufficient weight gain and LBW, using the adaptations of the American Committee adopted in Brazil, raise further questions regarding the definition both of the cut-off points to be used when classifying pre-gestational nutritional status and of those for establishing low height for the Brazilian population.

Previous evidence has also given rise to debate as to the universality of the pre-gestational BMI cutoff points adopted by the IOM, in so far as anthropometric values vary from one ethnic group to another, which suggests that different recommendations should be drawn up. 37-39

Hulsey et al. 40 found that lower than adequate maternal weight gain entails a greater likelihood of very low birth weight and moderate low birth weight, when compared to women with adequate weight gain. According to the ranges proposed by the $\mathrm{IOM}(\mathrm{OR}=1.4$ and 1.9 , respectively).

The fact that the proposal adapted from Atalah et al. 20 was not able to predict LBW, according to the analysis of the curve design, might be due to the lack of association between gestational BMI values and weight gain ranges recommended for a favorable birth weight outcome.

More recently, Villamor and Cnattingius ${ }^{41}$ have presented consistent epidemiological evidence that even a small increase in BMI during intervals between pregnancies may lead to deleterious effects on maternal health and infant well-being, regardless of woman's status vis-à-vis overweight or obesity. These findings suggest there is a need for more studies aiming to classify maternal nutritional status and, consequently, the adequacy of the recommended weight gain ranges.

The choice of anthropometric indicators to be used in practice, therefore, depends greatly on their ability to diagnose alterations in nutritional status during pregnancy and to identify changes resulting from interventions. The WHO, 12 in a collaborative study of maternal anthropometry and obstetric outcome, recognizes that such indicators must display a good level of sensitivity and specificity if they are to classify the maternal nutritional status adequately and to identify risks for obstetric outcomes, above all LBW, and undesirable incidents during gestation.

The significant association between the adoption of the adapted Brazilian Ministry of Health 19 for pregestational nutritional diagnosis according to the criteria of the WHO,21 and the SE and SP values for prediction of LBW further suggests that this method is the most appropriate.

The sensitivity, specificity and positive predictive value depend on the association between a risk factor and a certain result. 12 The SE and SP values found for different proposals were very similar and therefore are significantly associated with determining factors for low weight (Table 4). Most of the studies show higher specificity than sensitivity, and this was also observed in this analysis. However, it is important to point out that higher sensitivity values were achieved using internationally-used proposals, in which specificity and sensitivity vary between $70 \%$ and $35 \%, 12$ respectively. It can be observed that PPV values were low, and this may be due to the low prevalence of the LBW outcome under analysis, since the prevalence of events interferes with PPV. 42

However, a good indicator must have a high predictive or effect ability and a narrow reliability interval, and it must be convenient, sensitive and specific to screening and efficient, with a low number of false classifications. On the other hand, the efficiency or accuracy test minimizes the number 
of false classifications, whether they be positive or negative.

Although the aforementioned proposals appeared to be able to predict LBW in cases of inadequate maternal weight gain, the Brazilian Ministry of Health's adapted version ${ }^{19}$ using the $\mathrm{WHO}^{21}$ cut-off points for classification of initial anthropometric evaluation combines a greater number of those requirements associated with a higher OR. It can therefore be suggested that pre-gestational BMI cutoff points based on the values commonly adopted for adult women may be the most adequate method for establishing gestational weight gain.

It is believed that weight gain ranges may be the same as those proposed by the IOM, 14,15 because they were originally established using US national data, collected in 1980 as a basis, for pregnancies lasting from 39 to 41 weeks and birth weights ranging from 3 to $4 \mathrm{~kg}$, with an operational definition of favorable obstetric outcome.

This study again raises the question of the recommended minimum weight gain for low height pregnant women $(<1.57 \mathrm{~m})$, according to the recommendations by the IOM.14 It is suggested that the value considered by the American committee represents an overestimate for the Brazilian population. This finding may be due to the difference in the average height for each population, which would be in accordance with other studies carried out in Latin America, which take low height women to be those $<1.50 \mathrm{~m}$. In Brazil, da Silva, ${ }^{43}$ in a study evaluating the correlation between maternal height and LBW in pregnant adolescents, showed that there is a correlation between heights $<1.50 \mathrm{~m}$ and LBW.

In view of the facts presented in this study, it is extremely important to select a method for maternal anthropometric assessment to be used in prenatal care practice which is adequate, easy to apply and associated with a favorable obstetric outcome, and which can also be easily incorporated into basic care. Furthermore, this should be one of the topics addressed when evaluating the quality of prenatal care.

The definition of reference values must meet criteria, such as the nature of the population being attended, the design of (ideally) longitudinal studies and an adequate sample size, using the epidemiological concepts of sensitivity to justify the choice.

Using the results reported in this study, a high degree of sensitivity, at its best point of specificity, associated with the highest PPV and accuracy in the proposal recommended by the Brazilian Ministry of Health, ${ }^{19}$ using the $\mathrm{WHO}^{21}$ cut-off points for adults in pre-gestational BMI assessment appears to be the most adequate method for nutritional diagnosis with a view to prediction of LBW in this population.

Further studies need to be carried out in the Brazilian population in order to identify the low height point related to undesirable obstetric outcomes such as LBW and cephalo-pelvic disproportion.

The use of self-reported pre-gestational weight and the inclusion of pregnant smokers are two of the limitations of this study. Nevertheless, in a preliminary study with portion of the sample, and according to the literature, self-reported and measured weights appear to concord adequately. The fact that gestational age was not included in the logistic regression model is due to its strong predictive association with LBW.

Much still needs to be found out regarding the best method for anthropometric assessment of pregnant women. Efforts must therefore be made to solve this old dilemma, encouraging studies to validate methods, with a view to clearly identifying the most adequate methods for anthropometric assessment of pregnant women, with a potential impact on mother and child health in different populations. Obstetric outcomes other than LBW should also be investigated.

\section{Acknowledgement}

The authors would like to thank the Brazilian agencies, Conselho Nacional do Desenvolvimento Científico e Tecnológico (CNPq) and Fundação Carlos Chagas Filho de Amparo à Pesquisa do Estado do Rio de Janeiro (FAPERJ), for their financial support. We also thank the directors of the Maternidade Escola of the Universidade Federal do Rio de Janeiro, Drs. Joffre Amin Júnior and Rita Bornia, for indispensable support in conducting the study; and the volunteer interns and scientific initiation scholarship students who helped with the data collection. Special thanks go to Dr Hermogenes Chaves Netto for the valuable consultancy services he provided for this study. 


\section{Referências}

1. Brennand EA, Dannenbaum D, Willows ND. Pregnancy outcomes of First Nations women in relation to pregravid weight and pregnancy weight gain. J Obstet Gynaecol Can. 2005; $27: 936-44$

2. Cedergren M. Effects of gestational weight gain and body mass index on obstetric outcome in Sweden. Int J Gynaecol Obstet. 2006; 93: 269-74.

3. Henriksen T. Nutrition and pregnancy outcome. Nutr Rev. 2006; 64: S19-S23.

4. Kruger HS. Maternal anthropometry and pregnancy outcomes: a proposal for the monitoring of pregnancy weight gain in outpatient clinics in South Africa. Curationis. 2005; 28: 40-9.

5. WHO (World Health Organization). Meeting of advisory group on maternal nutrition and low birth weight. Geneva: 4-6 December; 2002. [consulted on: acesso em: 28 jul. 2008. Avalilable from: www.who.int/nutrition/publications/advisory_group_lbw.pdf

6. WHO (World Health Organization). Technical consultation towards the development of a strategy for promoting optimal fetal development. Geneva: 25-27 November; 2003. [consulted on: 2008 Jul. 28]. Available from: http://www.who.int/nutrition/publications/feto_pub/en/inde x.html.

7. WHO (World Health Organization). Promoting optimal fetal development: report of a technical consultation. Geneva, 2006. [consulted on: 2008 Jul. 2008]. Available from: www. who.int/LinkFiles/Making Pregnancy_Safer Optimalfetal_dev.pdf

8. Coelho KS, Souza AI, Batista Filho M. Avaliação antropométrica do estado nutricional da gestante: visão retrospectiva e prospectiva. Rev Bras Saúde Matern Infant. 2002; 2: 57-61.

9. Mohanty C, Prasad R, Srikanth AR, Ghosh JK, Singh TB, Das BK. Maternal anthropometry as predictors of low birth weight. J Trop Pediatr. 2006; 52: 24-9.

10. Oliveira AF, Gadelha AMJ, Leal MC, Szwarcwald CL. Estudo da validação das informações de peso e estatura em gestantes atendidas em maternidades municipais no Rio de Janeiro, Brasil. Cad Saúde Pública. 2004; 20 (Suppl 1): 92100 .

11. Wells CS, Schwalberg R, Noonan G, Gabor V. Factors influencing inadequate and excessive weight gain in pregnancy: Colorado, 2000-2002. Matern Child Health J. 2006; 10: 5562.

12. WHO (World Health Organization). Who Collaboraive Study. Maternal anthropometry and pregnancy outcomes. WHO Bulletin 1995; 73 (Suppl).

13. Ochsenbein-koible N, Roos M, Gasser T, Zimmermann R. Cross-sectional study of weight gain and increase in BMI throughout pregnancy. Eur J Obstet Gynecol Reprod Biol. 2007; 130: 180-6.

14. IOM (Institute of Medicine). Nutrition during pregnancy and lactation: an implementation guide. Washington, DC: National Academy Press; 1990.
15. IOM (Institute of Medicine). Nutrition during pregnancy. Washington, DC: National Academy Press; 1992.

16. Gibson RS. Principles of nutritional assessment. Oxford: Oxford University Press; 2005.

17. Brasil. Ministério da Saúde. Assistência pré-natal: manual técnico. Brasília, DF; 2000.

18. Schwarcz R, Díaz AG, Fescina R, Belitzky R, De Mucio B, Delgado L, Rosselló JLD. Normalização do cuidado da saúde materno-infantil. Saúde reprodutiva materna perinatal. São Paulo: OPAS; 1996. (Publicação Científica, n. 1321.03).

19. Brasil. Ministério da Saúde. Pré-natal e puerpério: atenção qualificada e humanizada: manual técnico. Brasília, DF; 2005 .

20. Atalah E, Castillo C, Castro R, Aldea A. Propuesta de un nuevo estándar de evaluación nutricional en embarazadas. Rev Med Chile. 1997; 125: 1429-36.

21. WHO (World Health Organization). Physical status: the use and interpretation of report anthropometry: report of a WHO Expert Committee; 1995. Geneve, 1995.

22. Coelho CSP. Deficiência de vitamina A no binômio mãefilho e distribuição intraplacentária de retinol [tese]. Rio de Janeiro: Escola Nacional de Saúde Pública da Fundação Oswaldo Cruz; 2003.

23. Saunders C, Leal MC, Gomes MM, Campos LFC, Silva BAS, Lima APPT, Ramalho RA. Gestational night blindness in women treated at a public maternity hospital in Rio de Janeiro, Brazil. J Health Popul Nutr. 2004; 22: 348-56.

24. Abrams B, Parker JD. Maternal weight gain in women with good pregnancy outcome. Obstet Gynecol. 1990; 76: 1-7.

25. Capurro H, Konichezky S, Fonseca D, Caldeyro-Barcia R. A simplified method for diagnosis of gestational age in the newborn infant. J Pediatr. 1978: 93: 120-2.

26. Hosmer DW, Lemeshow S. Applied logistic regression. New York: Wiley; 1989.

27. Hulsey TC, Neal D, Bondo SC, Hulsey T, Newman R. Maternal pregnancy body mass index and weight gain related to low birth weight in South Carolina. South Med J. 2005; 98: 411-15.

28. Marcondes F, Rosso P. A weight gain chart for pregnant women designed in Chile. Matern Child Nutr. 2005; 1: 7790 .

29. Doherty DA, Magann EF, Francis J, Morrison JC, Newnham JP. Pre-pregnancy Body Mass Index and pregnancy outcomes. Int J Gynaecol Obstet. 2005; 95: 242-7.

30. NRC (National Research Council), IOM (Institute of Medicine). Influence of pregnancy weight on maternal and child health: workshop report. Washington, DC: The National Academy Press; 2007.

31. Jonhson JW, Yancey MK. A critique of the new recommendations for weight gain in pregnancy. Am J Obstet Gynecol. 1996; 174 (1 Part 1): 254-8.

32. Nucci LB, Duncan BB, Mengue SS, Branchtein L, Schmidt MI, Fleck ET. Assessment of weight gain during pregnancy and general pre-natal care services in Brazil. Cad Saúde Pública. 2001; 17: 1367-74. 
33. Brynhildsen J, Sydsjo A, Norinder E, Selling KE, Sydsjo G. Trends in body mass index during early pregnancy in Swedish women 1978-2001. Public Health. 2006; 120: 3939.

34. Villar J, Bergsjo P. WHO antenatal care randomized trial: manual for the implementation of the new model. Genebra: WHO Antenatal Care Trial Research Group; 2003. [consulted on: 2006 May 12]. Available from: http://www.who.int/reproductive-health/publications/RHR $01 \_30 /$.

35. Kilsztajn S, Rossbach A, Carmo MHN, Sugahara GTL. Assistência pré-natal, baixo peso e prematuridade no Estado de São Paulo, 2000. Rev Saúde Pública. 2003; 37 : 303-10.

36. Helms E, Coulson CC, Galvin SL. Trends in weight gain during pregnancy: a population study across 16 years in North Carolina. Am J Obstet Gynecol. 2006; 194: 32-4.

37. Murakami M, Ohmichi M, Takahashi T, Shibata A, Fukao A, Morisaki N, Kurachi H. Prepregnancy Body Mass Index as an important predictor of perinatal outcomes in Japanese. Arch Gynecol Obstet. 2005; 271: 311-5.

38. Rached-Paoli I, Henríquez G, Azuaje-Sânchez A. Efetividad del Indice de Masa Corporal en el diagnóstico nutricional de gestantes. Arch Latinoam Nutr. 2005; 55: 42-6.

Recebido em 12 de março de 2008

Versão final apresentada em 18 de março de 2009

Aprovado em 13 de abril de 2009
39. Wong W, Tang NL, Lau TK, Wong TW. A new recommendation for maternal weight gain in Chinese women. J Am Diet Assoc. 2000; 100: 791-6.

40. Hulsey TC, Neal D, Bondo SC, Hulsey T, Newman R. Maternal pregnancy Body Mass Index and weight gain related to low birth weight in South Carolina. South Med J. 2005; 98: 411-15.

41. Villamor E, Cnattingius S. Interpregnancy weight change and risk of adverse pregnancy outcomes: a populationbased study. Lancet. 2006; 368: 1164-70.

42. Pereira MG. Aferição dos eventos. In: Pereira MG. Epidemiologia: teoria e prática. Rio de Janeiro: Guanabara Koogan; 2005. p. 358-76

43. Da Silva AFF. Gestação na adolescência: impacto do estado nutricional no peso do recém-nascido [dissertação]. Curitiba: Ciências da Saúde, Programa de Pós- Graduaçăo em Medicina Interna da Universidade Federal do Paraná; 2005 . 